\title{
STUDIES WITH PURIFIED HOUSE DUST ALLERGEN AND OBSERVATIONS ON THE NATURE OF ITS POLYPEPTIDE CONSTITUENT
}

\author{
L. BERRENS \\ Dermatological Department*, Academic Hospital, State University, Utrecht (The Netherlands)
}

(Received August 1 3th, I962)

\section{SUMMARY}

Purified house dust allergen has been subjected to several analytical procedures. Electrophoretic and ultracentrifugal studies showed the allergen to be a mixture of closely related skin-reactive mucoproteins. Dinitrophenylation of the allergen indi-cated the carbohydrate moiety to be connected to the polypeptide by $\mathrm{N}$-glycosidic linkages. Only a few of the molecules probably have a free (alanine)- $\alpha$-amino end group. Amino acids are readily released from the carboxyl end of the peptide chain by treatment with alkali. The allergen is resistant to the action of trypsin and chymotrypsin, but is destroyed by incubation with pepsin.

The significance of these findings is discussed.

In a recent study' on the purification of the house dust allergen, we expressed some doubt about the homogeneity of the compound, because the sedimentation pattern in the ultracentrifuge suggested it to be a polydisperse mixture of closely related mucoproteins. We have since obtained further evidence for this apparent polydispersity, together with additional information on the gross chemical structure of the allergen molecules.

Purified house dust allergen was obtained in a large quantity from pooled house dust** as previously described ${ }^{1}$. The final product was reprecipitated once with acetone to remove a small amount of polysaccharide impurities, and was obtained as a lightbrown, lyophilized powder. Crude house dust as a rule contains $25-50 \mathrm{mg}$ of the antigen $/ \mathrm{kg}$ dust.

The allergen contained $6 \%$ protein nitrogen (micro-Kjeldahl) and $28 \%$ bound carbohydrate, expressed as galactose (determined with the orcinol reagent ${ }^{2}$ ), in the form of galactose, arabinose and xylose. In contrast to the findings of VANNIER AND CAMPBELL ${ }^{3}$, we have in repeated experiments failed to detect more than $\mathrm{I} .5 \%$ of bound uronic acids in our preparation (Dische method ${ }^{4}$ ). The allergen possessed the same skin reactivity and specificity as previously described ${ }^{1}$, positive skin reactions in atopic patients being obtained with $0.0 \mathrm{I}-0.02 \mu \mathrm{g}$ intracutaneously. Moreover, provocation tests with the aerosolized allergen were specifically positive.

House dust allergen was found to contain no tryptophan, as assayed by the

* Head: Prof. Dr. L. H. Jansen

** We are very much indebted to the N.V. Organon, Oss for a large-scale extraction of house dust. 
method of SPIES AND ChAMBERS 5 . The presence of tyrosine in the polypeptide moiety of the allergen molecules was deduced from its ultraviolet absorption spectrum (Fig. I). The Millon reaction, moreover, was positive. The allergen was estimated to contain about $\mathrm{I} .5 \%$ tyrosine; our previous failure to detect the amino acid on paper chromatograms of acid hydrolyzates must be attributed to the reaction of tyrosine with the relatively large amount of sugars released during hydrolysis.

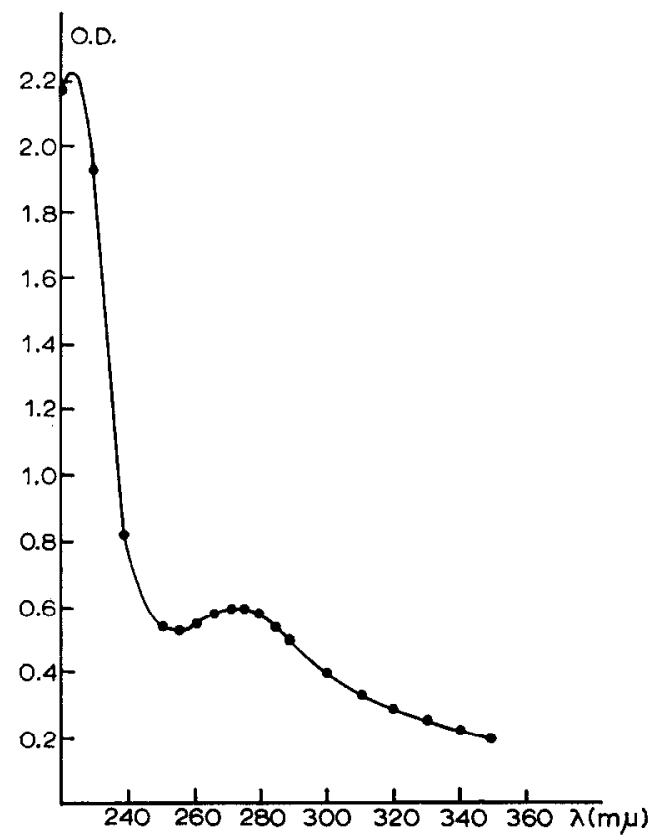

Fig. I. Ultraviolet absorption spectrum of purified house dust allergen in $0.1 \mathrm{I}$ IICl (I-cm cell).

\section{a. Mcthods}

\section{ELECTROPHORESIS STUDIES}

Paper electrophoresis was carried out on Schleicher and Schüll paper $2043 \mathrm{~b}$. with a $5 \%$ solution of the purified allergen in barbiturate buffer $\mathrm{pH} 8.6(\mu=0.05)$ in a conventional horizontal apparatus. A constant current of $2 \mathrm{~mA}$ per strip of $5 \mathrm{~cm}$ width was passed for a period of 4-5 h. Fixation was done by heating for Io min at $\mathrm{IOO}^{\circ}$; protein staining and elution were carried out with amidoblack as described by OOSTERHUis, and bound carbohydrates were visualized with periodate-Schiff reagent ${ }^{7}$. Agar gel-electrophoresis was carried out on microscope slides as outlined by WIEME ${ }^{8}$ for $\mathrm{I} 5 \mathrm{~min}$ at $20 \mathrm{~mA}$ per slide.

\section{b. Results}

The purified allergen migrates rapidly towards the anode on paper strips at pH 8.6, a distance of about $5.5 \mathrm{~cm}$ being covered in $4 \mathrm{~h}$ (Fig. 2). A strong tendency towards tailing was noted, both on paper and in agar slides. The mobility of the allergen is intermediate between the $\alpha_{2}$ - and $\beta_{1}$-globulins of normal human serum under the same conditions. The binding capacity for the protein dye proved to be relatively small; better results were obtained with carbohydrate stains (Fig. 3). Electrophoresis 
at $\mathrm{pH} 2.4$ in glycine-HCl buffer (0.05 $M$ ) showed the allergen to migrate as a more compact band which moved very slowly towards the cathode (about $2.5 \mathrm{~cm}$ from the point of application in $\mathrm{I} 6 \mathrm{~h}$ ). From these results the isoelectric point of the allergen was estimated to be at about pH 3.I, at which pH it does, however, not precipitate.

It is of interest to note that the positions of the stainable protein and carbohydrate material on strips, cut in half lengthwise, exactly overlapped at both pH values. This result may be taken as additional evidence for the existence of firm (covalent) bonds between the polypeptide and carbohydrate constituents of the allergen molecules.

It would seem that our purified allergen is identical with RimingTon's coloured "fast-moving component" "; we could not detect any other distinct components when staining was done with amidoblack or the fuchsin reagent on the electropherograms. Although, therefore, the electrophoretic studies did not uncover the presence

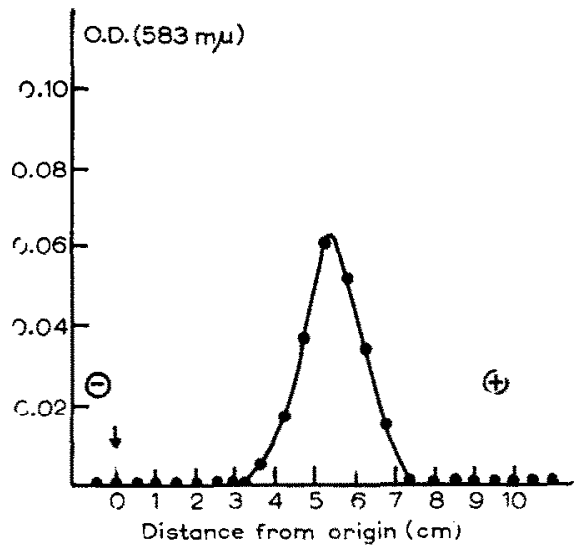

Fig. 2. Elution pattern of a paper electropherogram of the purified house dust allergen (ro $\mu 15 \%$ solution); duration: 4 h at $\mathrm{I} 5 \mathrm{O}$ V and $2 \mathrm{~mA}$; barbiturate buffer $\mathrm{pH} 8.6, \mu=0.05$. Stain: amidoblack Io B. Eluent: methanol-buffer $=\mathrm{I}: \mathrm{I}(5 \mathrm{ml})$

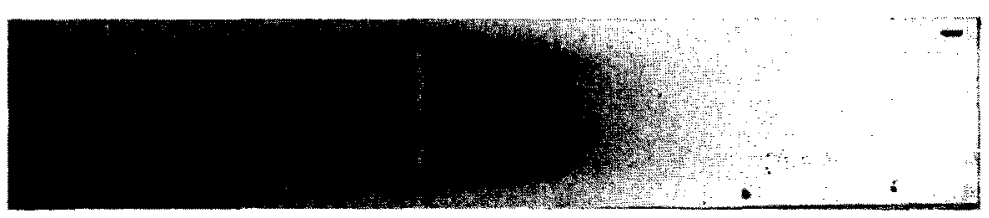

Fig. 3. Agar electropherogram of the purified house dust allergen. Time of run: 15 min at $220 \mathrm{~V}$ and $20 \mathrm{~mA}$. Barbiturate buffer $\mathrm{pH} 8.6, \mu=0.04$. Stain: periodate-fuchsin. The positive electrode is to the left.

of impurities, there is little doubt that the purified allergen itself consists of a very heterogeneous mixture of related mucoproteins. 


\section{ULTRACENTRIFUGAL MEASUREMENTS}

Sedimentation studies were performed in a Spinco model E ultracentrifuge with a $\mathrm{I} \%$ solution in sodium acetate buffer $\mathrm{pH} 5.5, \mu=0 . \mathrm{I}$, and in barbiturate buffer $\mathrm{pH}$ $8.6, \mu=$ o.I. In both media the allergen sediments in a very diffuse single peak which indicates a high degree of polydispersity (Fig. 4). Sharper peaks were observed in borate buffer $\mathrm{pH} 7.5$, owing to the formation of strong complexes between borate ions and the carbohydrate moiety of the antigen; the increased acidity of these borate complexes, however, made these results less suitable for reliable interpretation.

The sedimentation constants obtained are shown in Table I (corrected to zero time).

Assuming the partial specific volume to have the usual value of about 0.75 , the mean molecular weight of the allergen molecules would be about 20000-25000.

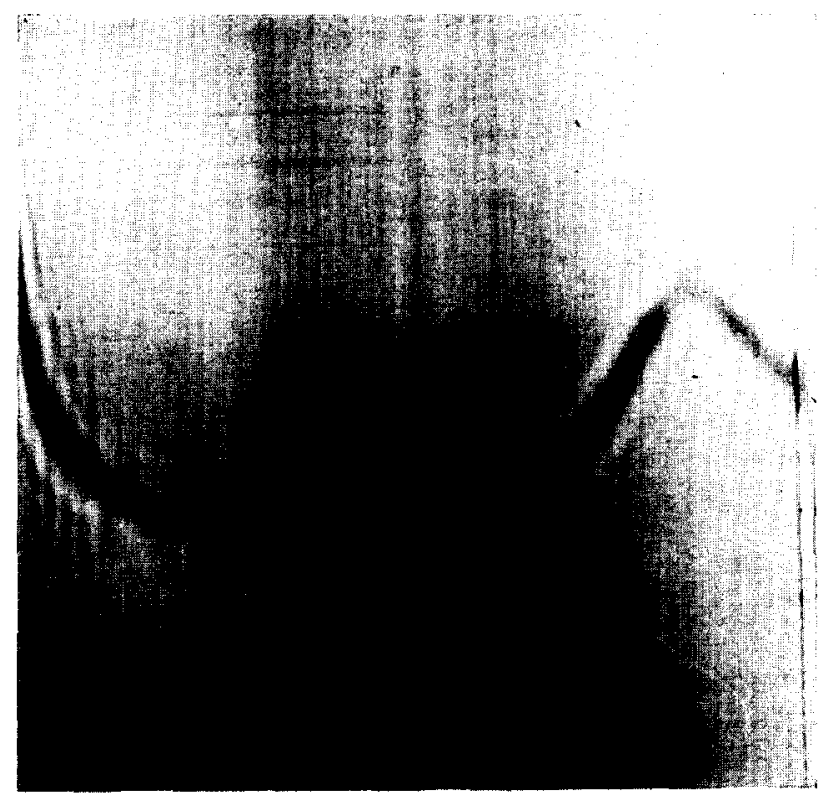

Fig. 4. Sedimentation pattern of $\mathrm{I} \%$ purified dust allergen in barbiturate buffer $\mathrm{pH} 8.6, \mu=0 . \mathrm{I}$. Photograph taken $64 \mathrm{~min}$ after reaching full speed (59780 rev./min.). Angle: $5^{\circ}$. temp: $17^{\circ}$. Direction of sedimentation from right to left.

TABLE I

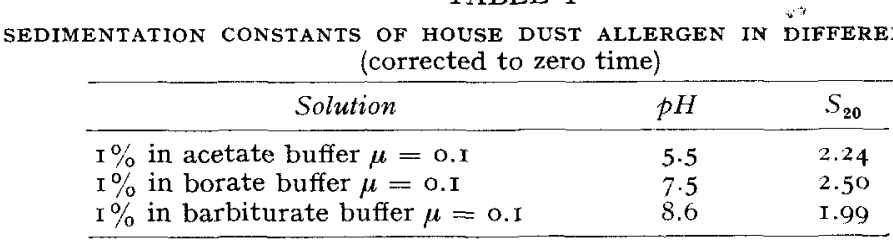

1I. PKOTEIN ENU-GROUPS AND INHLUENCE OF PROTEOLYTIC ENZYMES

\section{a. Free amino groups}

Although the general chemical characteristics of the allergen are those of a very complex organic acid, the (weak) binding of the dye amidoblack, and the opposite direction of electrophoretic mobility at pH 8.6 and 2.4 respectively might point to 
the presence of residual unsubstituted aminogroups. The negative ninhydrin reaction previously observed might be attributed to masking of amino groups by carbohydrates or to the length of the peptide chain.

In an attempt to establish the nature of the $\mathrm{N}$-terminal amino acid, $20 \mathrm{mg}$ of the allergen was reacted at $20^{\circ}$ with $20 \mu$ mole of dinitrofluorobenzene in aqueous $2 \%$ sodium bicarbonate for $2 \mathrm{~h}$ (ref. ro). Excess DNFB was removed from the alkaline solution by repeated ether extractions; the remaining solution was acidified to $\mathrm{pH} 3$ with hydrochloric acid and dialyzed against distilled water. The DNP-derivative was obtained by lyophilization as a yellow, easily soluble powder in a yield of I4 mg. The substance was hydrolyzed with $\mathrm{I} \mathrm{ml}$ of constant boiling hydrochloric acid at $100^{\circ}$ for $4 \mathrm{~h}$ and the yellow hydrolyzate was filtered, diluted with water and extracted with peroxide-free ether.

Ultraviolet spectroscopy of the aqueous layer revealed the presence of DNP-otyrosine only, DNP- $\varepsilon$-lysine being completely absent. From the observed extinctions at $300(0.774)$ and $390 \mathrm{~m} \mu(0.252)$ the recovery of DNP-o-tyrosine was calculated to amount to $0.23 \mathrm{mg}(\mathrm{I} \%)$; allowing for losses during hydrolysis this would mean that most of the tyrosine residues in the allergen had reacted with DNFB.

The DNP-amino acids in the ether layer were dissolved in $6 \mathrm{~N}$ ammonia after removal of ether. As suggested by KamiYama AND SCHMiD ${ }^{11}$ the amino acids were then regenerated from their DNP-derivatives by heating the ammoniacal solution in a sealed tube for $4 \mathrm{~h}$ at $100^{\circ}$. After the removal of ammonia over concentrated sulphuric acid the amino acids were finally chromatographed on paper.

Only a very faint spot of alanine could be detected on the chromatograms indicating that only few of the molecules in our preparation had an unsubstituted $\alpha$-amino end group.

The absence of free $\varepsilon$-lysine amino groups suggests that the carbohydrates are connected to the polypeptide via N-glycosidic linkages; further support for this assumption was obtained by studying the susceptibility of the allergen to enzymic digestion by trypsin (Section III c).

\section{b. Action of carboxypeptidase and influence of acid and alkaline media}

The results of the above experiments indicate that the acidity of the allergen is mainly due to a relative excess of protein carboxyl groups; the presence of a free $\alpha$-amino end group in at least some of the molecules suggests, moreover, that the carboxyl group of the C-terminal amino acid is unsubstituted. We verified this assumption by subjecting the allergen to the action of carboxypeptidase in alkaline solution.

The purified allergen $\left(5 \mathrm{mg}\right.$ ) was dissolved in $2 \mathrm{ml}$ of aqueous $0.1 \% \mathrm{NaHCO}_{3}$. At zero time I $\mathrm{ml}$ of a solution containing $0.1 \mathrm{mg}$ of crystalline carboxypeptidase ("Worthington") was added and the reaction mixture was shaken at $37^{\circ}$; pretreatment of the enzyme suspension involved the addition of o.I $\mathrm{N} \mathrm{NaOH}$ to $\mathrm{pH}$ II and immediate readjustment to $\mathrm{pH} 8$ with o.I $N \mathrm{HCl}$ to give a clear colourless solution. Suitable aliquots were withdrawn from the incubation mixture at set intervals and pipetted into glass-stoppered tubes containing $50 \mathrm{mg}$ of purified Dowex-50 $\mathrm{W} \times 8$ (100-200 mesh) in the $\mathrm{H}^{+}$-form ${ }^{12}$. The released amino acids were eluted with $5 \%$ ammonia and the eluate was taken to dryness in vacuo over $\mathrm{H}_{2} \mathrm{SO}_{4}$. The amino acids were finally identified by paper chromatography. 
Unfortunately, the purified allergen turned out to be very unstable in sodium bicarbonate solution; the control experiment (incubation in $0.1 \% \mathrm{NaHCO}_{3}$ without added enzyme) showed that under these conditions free amino acids are rapidly split off. The addition of the enzyme, though increasing the rate of hydrolysis, did not appreciably alter the sequence of amino acid release.

The results of a typical (qualitative) experiment are recorded in Table II.

From these results the conclusion may be drawn that in all probability the amino acid serine is at the end of the peptide chain, and that its carboxyl group is indeed free. Also, the carboxyl end of the polypeptide moiety obviously is a relatively labile part of the allergen molecules. In acid solution, for instance, the same amino acids are released from the allergen, though under less mild conditions of hydrolysis.

In preliminary experiments designed for the selective removal of sugars from the

TABLE II

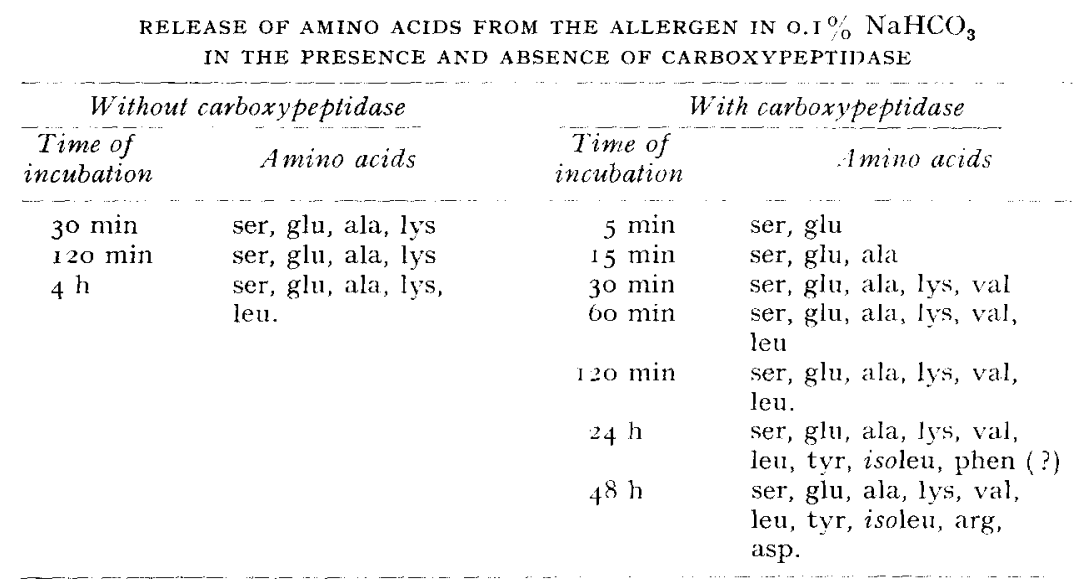

allergen $20 \mathrm{mg}$ of the antigen was treated with I $\mathrm{ml}$ of $0.1 \mathrm{~N} \mathrm{HCl}$ at $100^{\circ}$; $10-\mu \mathrm{l}$ aliquots were withdrawn after different periods of hydrolysis and their composition examined by paper chromatography. Monosaccharides are very rapidly released under these conditions, spots of arabinose and xylose appearing after $30 \mathrm{~min}$, followed by galactose within $\mathrm{I} h$. Simultaneously, protein hydrolysis occurs, serine appearing in the hydrolyzate after I $h$, followed shortly afterwards by lysine and glutamic acid. In separate experiments the recovery of antigen after hydrolysis for $1.5 \mathrm{~h}$ (by precipitation with acetone, dialysis and lyophilization) amounted to only $50 \%$. The acid-treated antigen still contained as much as $25 \%$ combined carbohydrate and possessed unchanged skin-reactivity.

In our opinion the most important fact emerging from these studies is that we invariably found the nature of the amino acids and the sequence of their release to be exactly the same for samples of the purified dust allergen prepared from different batches of house dust.

The skin-reactivity and the antigen specificity thus seem to be associated with mucoprotein molecules possessing a definite amino acid composition. 


\section{c. Attack by proteolytic enzymes}

RimingToN ${ }^{\theta}$ has already noted that allergen preparations treated with trypsin do not lose their skin-reactive potency. We have studied the composition of trypsin digests of the allergen and have found the allergen to be resistant towards tryptic digestion.

The reaction mixture consisted of $5 \mathrm{mg}$ of the purified allergen in $2 \mathrm{ml}$ of ammonium acetate buffer $(0.2 M)$ pH 8.0 , to which Io $\mu$ l of $0.5 \%$ trypsin solution ("Worthington", $2 \times$ cryst.) was added; digestion was allowed to proceed for $16 \mathrm{~h}$ at $36^{\circ}$ and the reaction was stopped by the addition of hydrochloric acid to give $\mathrm{pH} 4$. The solution was then taken to dryness in vacuo over sodium hydroxide and the residue was examined for the presence of peptide fragments by high-voltage paper electrophoresis (pyridine-acetic acid-water buffer (I00:4:900) pH 6.5, for I h at $2000 \mathrm{~V}$ and $\mathrm{I} 50 \mathrm{~mA}$ )

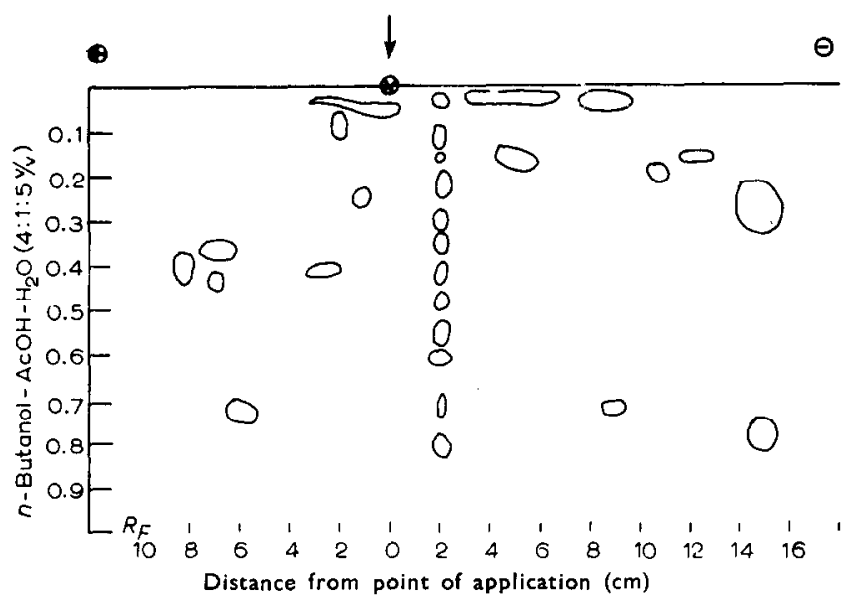

Iiig. 5. Peptide map of pepsin-digested house dust allergen. (For explanation, see text.)

and subsequent chromatography as described by ANFINSEN et al. ${ }^{13}$. After staining with ninhydrin, no peptides could be detected on the sheets; in some experiments only a very faint spot was observed moving very slowly towards the cathode, which might have been some amino acid split off by the alkaline treatment.

In similar experiments a remarkable resistance was noted against incubation with chymotrypsin.

The antigen, however, proved to be very susceptible to the action of pepsin. In a typical experiment $5 \mathrm{mg}$ of the allergen was digested at $37^{\circ}$ with $0.2 \mathrm{mg}$ of crystalline pepsin in $2 \mathrm{ml}$ of $0 . \mathrm{I} N$ acetic acid for a period of $\mathrm{I} 6 \mathrm{~h}$; the reaction was stopped by heating the solution for $5 \mathrm{~min}$ at $100^{\circ}$ and the peptide-solution, after removal of denatured pepsin by centrifugation, was dried over sodium hydroxide. Samples corresponding to about $2 \mathrm{mg}$ of material were then subjected to high-voltage electrochromatography. Although the resulting peptide-map showed some large tails (presumably due to glycopeptides) it was evident that the allergen is extensively destroyed by the action of pepsin. A representative peptide-tracing is given in Fig. 5 . 
It should be noted that the previous successive treatment with $8 M$ urea, mercaptoethanol and iodoacetic acid did not influence the results with either of the enzymes used.

Again, the same results were obtained with samples of the purified dust allergen extracted from different batches of house dust.

In view of the specificity requirements of trypsin for proteolytic action, the negative results with this enzyme are consistent with the absence of available $\varepsilon$-lysine amino groups (Section III a).

\section{PRECIPITATION WITH A CATIONIC DETERGENT}

By virtue of its high content of conjugated sugars, the allergen constitutes a suitable substrate for precipitation with a cationic detergent from borate solutions. The addition of an equal volume of $0.1 \%$ cetyltrimethylammonium bromide to a solution of the allergen in sodium borate solution at $\mathrm{pH} 9.0-9.5$ in fact immediately produces an insoluble flocculent precipitate. Precipitation does not occur in borate buffers at $\mathrm{pH} 7.0$.

Dissociation of the insoluble complex is rapidly brought about by shaking it with o.I $N$ hydrochloric or acetic acid. The allergen may then be recovered by precipitation with acetone-dioxane $=3: \mathrm{I}$ and the excess detergent removed by passage of an aqueous solution through a column of Dowex $-50\left(\mathrm{H}^{+}\right)$.

Although BARKER AND TROTTER successfully applied this method to the purification of trichophytin ${ }^{14}$, it proved to be of little value in our case because the inhomogeneity in the carbohydrate distribution remains unchanged. Consequently, the relative specific activity of the purified dust allergen was not increased by this treatment.

Similarly, the ready adsorption of the allergen on zinc oxide turned out to be useful only as a quantitative method for the rapid recovery of antigen from large volumes. The allergen, finally, is also very easily adsorbed by a suspension of aluminum phosphate in saline; this may be a valuable tool in the study of its immunological behaviour.

\section{DISCUSSION}

The last few years have witnessed considerable progress in the isolation and study of highly purified inhalant allergens. A definite pattern in the general chemistry of this class of compounds gradually emerges which enables a reliable comparison of the house dust allergen with other allergens. The apparent heterogeneity of the dust allergen, for instance, is a striking property common to ragweed pollen allergen ${ }^{15}$, grass pollen allergen ${ }^{16}$ and the cottonseed allergen ${ }^{17}$. Like the dust allergen, moreover, these antigens have all been found to be complex glyco- or mucoproteins which may each show a considerable individual variation in carbohydrate content. We have previously interpreted these characteristic features as a reflection of the mode of formation of inhalant allergens ${ }^{18}$, i.e. by Maillard reactions between the polypeptide and carbohydrate constituents of decomposing cellular material. The presence of $\mathrm{N}$-glycosidic linkages through the $\varepsilon$-lysine residues of the dust allergen would seem to support this hypothesis. Possibly, also, some sugar residues are attached via the amino group of the $\mathrm{N}$-terminal amino acid.

For clinical purposes attempts at the further purification of the dust allergen 
seem to be of little practical value. Thus, the purified allergen may be readily adsorbed upon DEAE-cellulose and a significant amount of skin-reactive material can be eluted with $0.5 \mathrm{~N}$ sodium chloride. Increasing the sodium chloride concentration of the eluent to I.O $N$ and I.5 $N$ respectively results in the elution of two additional preparations with about equal skin reactivity and with the same antigen specificity.

The recent results of LIETZE AND REED ${ }^{19}$ in this respect deserve some comment. Their dust allergen preparation, obtained by the treatment of a crude alkaline extract with alcohol to a concentration of $50 \%$, could be resolved into two distinct groups of molecules by chromatography on DEAE-Sephadex. The fact that these materials had a different antigen specificity can probably be attributed to contamination with dandruff or feather allergens, because their starting material contained a large amount of material precipitable below pH 6.I which they did not remove before chromatography. The distribution of the allergen molecules in the "dust" peak, however, showed the typical polydispersity characteristic of our preparation. Their conclusion that they obtained an allergen different from both ours and VANNIER AND CAMPBELI's ${ }^{3}$ must be rejected because neither our product, nor accompanying polyuronides are removed by their isolation procedure. The extraction of house dust with strong alkali, moreover, seems to be contra-indicated because of its decomposing effect upon the allergen moleculcs (Sections IIIb).

We agree, however, that the house dust allergen consists of a mixture of related mucoproteins; the heterogeneity, presumably, is exclusively localized in their respective carbohydrate moieties. Although it is tempting to speculate on the site of the antigen specificity in these molecules, its definite localization within the polypeptide constituent must await further evidence.

\section{ACKNOWLEDGEMENTS}

Thanks are due to Mr. H. VREEMAN for the ultracentrifugal analyses and to Miss J. JANSEN for skilled technical assistance.

\section{REFERENCES}

1 L. Berrens and E. Young, Intern. Arch. Allevgy Appl. Immunol., i9 (1961) 34 I.

2 J. BRÜCknER, Biochem. I., 60 (19.55) 200.

3 W. E. Vannier and D. H. Campbell, J. Allergy, 30 (I959) I98.

4 Z. Dische, J. Biol. Chem., I67 (I947) I 89.

5 J. R. SPIES ANd D. C. Chambers, Anal. Chem., 2 I (1949) 1249.

6 H. K. Oosterhuis, J. Lab. Clin. Med., 44 (19.54) 280.

7 E. Kö̈w and A. Grönwall, Scand. J. Clin. Lab. Invest., 4 (1952) 3.

8 R. Wieme, Clin. Chim. Acta, 4 (I959) 3 I 7.

* K. Maunsell, C. Rimington and D. E. Stillwell, Brit. J. Exptl. Pathol., 28 (i947) 309.

10 F. SANGER, Biochem. J., 39 (I945) 507.

11 S. Kamiyama and K. Schmid, Biochim. Biophys. Acta, 58 (1962) 8o.

12 H. Fraenkel-Conrat, J. I. Harris and A. L. Levy, in D. Glick (Ed)., Methods of Biochemical Analysis, Vol. 2, Interscience, New York, I955, p. 359.

13 A. M. Katz, W. J. Dreyer and Ch. B. Anfinsen, J. Biol. Chem., 234 (1959) 2897.

14 S. A. Barker AND M. D. Trotter, Natuve, I 88 (I960) 232.

15 D. J. Lea and A. H. Sehon, Intern. Arch. Allergy Appl. Immunol, 20 (Ig62) 203.

16 R. Augustin, Acta Allergol., Suppl. III (I953) I94.

17 J. R. Spies, D. C. Chambers and E. J. Coulson, Arch. Biochem. Biophys., 84 (1959) 286.

18 L. Berrens, Allergie u. Asthma, 8 (I962) 75 .

19 A. Iitetze And Ch. E. ReEd, Intern. Arch. Allergy Appl. Immunol., 20 (I962) 344. 